The Labore Journal of Economics

$10: 1$ (Summer 2005) pp. 83-104

\title{
The Knowledge Divide: Education Inequality in Pakistan
}

\section{Haroon Jamal and Amir Jahan Khan"}

As economic activity becomes increasingly knowledge based, disparities in educational opportunity play a more important role in determining the distribution of income and poverty. A greater equity in the distribution of educational opportunities enables the poor to capture a larger share of the benefits of economic growth, and in turn contributes to higher growth rates. In contrast, large-scale exclusion from educational opportunities results in lower economic growth and persistent income inequality. This research appraises education inequalities in Pakistan at the district leve1. To summarize district performance in terms of education, a District Education Index (DEI) is prepared. Further, it explores the socioeconomic inequalities in education by linking DEI with the level of district economic development.

\section{Introduction}

"I go to school because I want to learn. People with education have a better life. But our school has many problems. The classes are very crowded, and there are no blackboards or chalk. Some children have textbooks, but the parents of the poor children cannot afford books, notepads, or pencils. It is hard for my parents to pay school fees. Many children in my village do not go to school because their parents are too poor. My brother and sister have both dropped out of primary school because my parents had no money."

The voice is that of a twelve year-old Tanzanian girl in the third grade of primary school (Watkins 2001, The Oxfam Education Report). These words summarize more powerfully than any statistics the reality behind the education crisis in poor countries.

\footnotetext{
* Authors are Principal Economist and Economist, respectively at the Social Policy and Development Centre (SPDC), Karachi. The views expressed are those of the authors and do not necessarily reflect the policies and views of SPDC.
} 
Education helps to improve living standards and enhance the quality of life, and can, thereby, provide essential opportunities for all. Many of the world's states, through international conventions and commitments, have recognized education as a human right. In a rapidly changing world, education has become more important than ever. Faced with increasing globalization, the rapid spread of democracy, technological innovation, the emergence of new market economies, and changing public/private role, countries need more highly educated and skilled populations, and individuals need added skills and information to compete and thrive.

Typically, poverty and inequality are perceived of in terms of income. Differences in income and wealth matter because they define opportunities for reducing poverty. But differences in income reflect deeper inequalities in life-chances, including inequalities in education. Wide income disparities tend to coexist with under-investment in human capital, that translates into lower long-run economic growth. The empirical evidence suggests that there is a high correlation between income and education levels, as well as between income and educational inequalities.

The relationship between education and income equality is linked to the returns associated with education. Consider the present situation where the nature of technological change and the globalization trend are manifested by a rapidly increasing relative demand for technologically skilled workers. If the demand for unskilled labor is contracting or growing at a slower rate than the demand for skilled labor, then wage inequalities will increase. The gap between rich and poor will then start to widen and income inequality will continue to grow. Moreover, if there is a large disparity in the educational opportunities between the rich and poor, mainly educated workers capture the benefits of economic growth. This, in turn, exacerbates income inequality.

Beyond the discussion on the importance of education for economic growth, the value of education to the individual is so high that access to education is recognized as a human right in international law. Countries ratifying the United Nations (UN) convention on the Rights of the Child recognize the right to education "on the basis of equal opportunity". Therefore to promote this right to education, access should be provided without any discrimination.

The characteristics to which discrimination in education provision could be linked are wide-ranging. Gender, ethnicity and disability are obvious examples and are explicitly mentioned by the UN Convention. But 
the list should also include spatial discrimination in terms of low or no provision of education facilities.

This research follows this direction and touches the surface by appraising education inequalities in Pakistan at the district leve1. To summarize district performance in terms of education, a District Education Index (DEI) is prepared which is explained in the following section. This section also describes the methodology and indicators for constructing the Index of Economic Development (IED). Principle findings are reported in Section 3, while the last section is reserved for concluding remarks.

\section{Measuring Performance and Inequality}

Education performance in its broader sense cannot easily be captured. In developing countries, even to get a simple 'input' factor such as enrollment poses problems. The most basic data is often unreliable, or in fact unavailable. There are questions regarding school attendance or enrollment data which is collected and published by various provincial authorities. To make the exercise less disputable or debatable as far as the data source is concerned, all education indicators are selected from the Population Census (Pakistan Census Organization, 1998). This approach makes the analysis somewhat restrictive (in the absence of educational attainment and quality) but is preferred so as to avoid any reservations regarding the quality of education data.

\subsection{District Education Index (DEI)}

Districts' educational status is measured through enrollment in various age cohorts and adult literacy rates. The Census provides age-wise student population. Three levels were chosen for the development of DEI student population or enrollment in age groups of 5-9 years, 10-14 years and 15-24 years. These levels represent primary, secondary and tertiary grades. Tertiary grade is further divided into general (arts or science) and technical (includes education programs of engineering, medicine, public health, commerce and business administration, teaching, agriculture and law) enrollment ratios. Adult literacy rate is defined as the ratio of literate persons (can read a newspaper and write a simple letter in any language) to the population of 10 years and above.

The above five indicators are simple rates (enrollment or literacy) and may easily be combined. Instead of assigning equal weight to each indicator, Principal Component Technique (PCA) of Factor Analysis is used to generate weights. The PCA searches for the linear combinations of the 
variables selected that account for the maximum possible variance in the data. This statistical procedure assigns the greatest weight to the variable which has the greatest variance (or dispersion). Similarly, the indicator with the lowest level of inequality will have the lowest weight. DEI is, therefore, the weighted average of five indicators with weights derived through a statistical procedure. To observe the provincial, regional and gender differences, DEI is computed separately for provinces, for rural and urban areas, and for male/female populations.

\subsection{Index of Economic Development (IED)}

The socioeconomic dimension can be included in the analysis through the calculation of the Concentration Index or Concentration Curve if the geographic units are ordered by socioeconomic status. Thus, pure inequalities in education are linked to economic development with the help of IED. Various attributes or indicators have been integrated to develop a composite Index of Economic Development. These indicators ${ }^{1}$ measure the economic potential and achieved levels of income and wealth; extent of mechanization and modernization of agriculture; housing quality and access to basic residential services; and development of transport and communications. A brief description of individual indicators is given below.

Household income and wealth is the most discussed welfare attribute in literature. Direct income data at provincial or district levels are not available; therefore various proxies are used to estimate the income and wealth position of a district. For the rural economy, cash value of agricultural produce per rural person and livestock per rural capita are used. All major and minor crops are considered to estimate the district's cash value from agriculture. This indicator is based on the aggregation of 43 crops, including fruits and vegetables. Different types of livestock have been aggregated by assigning weights as recommended by the FAO (Pasha and Hassan,1982) to reflect the capital value of various animals and poultry. For the urban part of a district, per capita value added in large-scale manufacturing is used to proxy the level of urban income. Value added by the small-scale component could not be included due to lack of data. On the assumption that there may be a direct link between the number of bank branches in a district and the volume of bank deposits, number of bank

\footnotetext{
${ }^{1}$ Diverse sources are used to gather data for the above indicators. Major sources include; District Census Reports, 1998, Provincial Census Reports, 1998, Agriculture Statistics of Pakistan, 1998-99, Provincial Development Statistics, Crop Area Production 1997-98, Census of Manufacturing Industries, 1995-96 etc. Further, to fulfill the missing gaps or for updating various information, unpublished data are obtained from the provincial Bureaus of Statistics, State Bank of Pakistan and the Ministry of Agriculture.
} 
branches per capita is used as a crude measure of the district's wealth. Per capita car ownership is also used to proxy the district's income and wealth in the urban areas.

Modernization of agriculture is another area of development which has direct or indirect effects on the prosperity and standard of living of the rural population. To capture the process of mechanization in agriculture, tractors per 1000 acres of cropped area is used. Consumption of fertilizer per 100 acres of cropped area is also used as the indicator of modernization in agriculture. In addition, irrigated area per 100 acres of cropped area is used to capture the access to canal irrigation systems and tube-wells.

Shelter is one of the basic needs, and housing conditions are one of the key determinants of the quality of life. For IED, the proportion of households using electricity, gas and inside piped water connections is used. The quality of housing stock is represented by the proportion of houses with cemented outer walls and RCC/RBC roofing. Rooms per persons is used to proxy adequate housing in a district.

Three indicators have been included to portray the level of development of the transport and communication sector in a district. Roads and the transportation network have a significant impact on socialization and modernization. Therefore, metalled road mileage per 100 square miles of geographical area of a district is included in the index. With regard to the availability of transport vehicles, a summary measure, viz., passenger load carrying capacity is included. Different vehicles are aggregated assigning weights as recommended in Pasha and Hassan (1982). Number of telephone connections per 1000 persons is also used to observe the distribution of this important indicator of the standard of living.

The index is also constructed using the Principal Component Analysis $^{2}$. The exercise was undertaken on the full sample (100 districts) and principal components were used to rank districts according to their economic level of development.

\subsection{Inequality Measures}

The measurement of disparities is an arduous task and no single statistical measure is able to capture its myriad dimensions. Recognizing these difficulties, various measures to highlight diverse dimensions of

2 Similar methodology is adopted by Filmer and Pritchett (1999) for exploring the effects of household wealth on educational attainments. 
inequalities are used in this study. The selected measures are briefly described in the following paragraphs.

\section{Maximum to Minimum Ratio (MMR)}

The highest to lowest ratio of DEI provides a measure of the range of national or provincial educational disparities. If this ratio is small (close to 1), then it would mean that the districts have a relatively equal level of education. If this measure is large, then the interpretation is more problematic, as it does not tell us if the high ratio is due to substantial variation in the distribution of DEI or the presence of outliers. Nevertheless, MMR provides a quick, easy to comprehend and politically powerful measure of regional inequality.

\section{Coefficient of Variation (CV)}

The coefficient of variation is one of the most widely used measures of regional inequality in the literature. The CV is a measure of dispersion around the mean. This dispersion can be calculated in a few different ways. The simple coefficient of variation is an un-weighted measure as given below:

$$
C V_{u} \equiv \frac{1}{\bar{I}}\left[\sum_{i=1}^{n}\left(I_{i}-\bar{I}\right)^{2}\right]^{1 / 2}
$$

where $I_{i}$ is the value of District Education Index, $\bar{I}$ is the mean value of DEI and $n$ is the number of districts. $C V_{u}$ varies from zero for perfect equality to $\sqrt{n-1}$ for perfect inequality. Although this measure can be used for comparisons of regional disparities across time, it is problematic for comparisons between provinces because the inequality value is sensitive to the number of districts in the province.

This problem is somewhat overcome by the 'weighted coefficient of variation', where each regional deviation is weighted by its share $\left(\frac{p_{i}}{P}\right)$ in the national or provincial population. This measure is calculated as given below:

$$
C V_{w} \equiv \frac{1}{\bar{I}}\left[\sum_{i=1}^{n}\left(I_{i}-\bar{I}\right)^{2} \frac{p_{i}}{P}\right]^{1 / 2}
$$


Here $C V_{w}$ varies from zero for perfect equality to $\sqrt{\frac{p-p_{i}}{P_{i}}}$ for perfect inequality. This is better then $C V_{u}$ for provincial comparison as the measure of inequality depends not on the number of districts but on the population proportion.

\section{Gini Index (Gini)}

The Gini Index like the coefficient of variation is also widely used in the inequality literature. Following Kakwani (1980), the Gini is computed as follows:

$$
\text { Gini } \equiv\left(\frac{1}{2 \bar{I}}\right)\left(\frac{1}{n(n-1)}\right)\left[\sum_{i=1}^{n} \sum_{j=1}^{m}\left|I_{i}-I_{j}\right|\right]
$$

The Gini Index provides a measure of resource inequality within a population. It is the most popular measure of inequality and summarizes the extent to which actual distribution of resource differs from a hypothetical distribution in which each person/unit receives an identical share. Gini is a dimensionless index scaled to vary from a minimum of zero to a maximum of one; zero representing no inequality and one representing the maximum possible degree of inequality.

\section{Concentration Curve (CC)}

To grasp the education inequalities with respect to the economic status of districts, concentration curves have been plotted for various levels of enrollment. A Concentration Curve or Index is closely related to the relative index of inequality, which is widely used in the literature of socioeconomic inequality in education and health. The curve plots the cumulative enrollment (on the y-axis) against the cumulative relevant population (on the $x$-axis), ranked by the Index of Economic Development. The idea is very much similar to the famous Lorenz Curve. But in contrast to the case of the Lorenz Curve, districts are not ranked by the distribution that is under investigation. Since the concern here is with economic inequalities in education rather than pure inequalities, enrollments are grouped according to economic status. If the curve coincides with the diagonal or line of equality, all children, irrespective of their socioeconomic status, enjoy the same enrollment ratios. If, as is more likely, the curve lies above the diagonal, enrollment rates are higher among the better-off and hence 
inequalities that favor the rich. The further the Concentration Curve lies from the diagonal, the greater the degree of inequality across socioeconomic groups.

\section{Major Findings}

Major findings are grouped in the three sub-sections. The first two sub-sections discuss socioeconomic inequalities in education, while the last sub-section explains pure inequalities in education through the DEI.

First, some comments on the education indicators chosen for this analysis warrant attention. Tables- 1 and 2 summarize levels as well as dispersion for these indicators. As we have taken student population in various age cohorts, a clear boundary between primary, secondary and tertiary levels is not feasible. Enrollment in the age cohort 5-9 indicates net primary enrollment rate. However, enrollment in the age cohort 10-14 represents both, over age primary students and net enrollment in secondary level. Similarly, over age secondary student and net tertiary enrollment are included in the age cohort 15-24. This goes to explain why the average level in enrollment $10-14$ is high as compared with net primary enrollment rate (Table-1). Therefore, primary, secondary and tertiary levels are indicatives and this caveat should be kept in mind while discussing enrollment rates $^{3}$.

\section{Table-1: Average Value of Components of DEI [Overall Scenario]}

\begin{tabular}{lccc}
\hline & Mean & Minimum & Maximum \\
\hline Enrollment 5-9 Years [Primary] & 33.56 & 3.74 & 74.78 \\
Enrollment 10-14 Years [Secondary] & 43.93 & 6.81 & 84.61 \\
General Enrollment 15-24 [Tertiary] & 17.53 & 2.14 & 44.18 \\
Technical Enrollment 15-24 Years & 0.34 & 0.00 & 3.28 \\
[Tertiary] & & & \\
Adult Literacy Rate & 34.90 & 10.37 & 70.45 \\
\hline
\end{tabular}

3 An alternative option was to compute combined enrollment rate for the 5-24 age cohort. But this option does not allow substitution among various levels of education. For instance, a shortfall in tertiary education may be substituted with primary level. A weighted average index with enrollment at various levels is, therefore, preferred. 
Table-2: Dispersion in Components of DEI [Overall Scenario]

\begin{tabular}{lccc}
\hline & $\begin{array}{c}\text { Maximum to } \\
\text { Minimum } \\
\text { Ratio }\end{array}$ & $\begin{array}{c}\text { Coefficient } \\
\text { of Variation } \\
\mathbf{( \% )}\end{array}$ & $\begin{array}{c}\text { Gini } \\
\text { Index } \\
\text { (\%) }\end{array}$ \\
\hline Enrollment 5-9 Years [Primary] & 20 & 62.58 & 29.79 \\
Enrollment 10-14 Years [Secondary] & 12 & 43.75 & 23.43 \\
General Enrollment 15-24 [Tertiary] & 21 & 47.46 & 22.85 \\
Technical Enrollment 15-24 Years & 3 & 166.63 & 43.13 \\
[Tertiary] & 7 & & \\
Adult Literacy Rate & 7 & 51.46 & 23.34 \\
\hline
\end{tabular}

Overall only 18 percent enrollment is evident in the age cohort 1524 years, which is reflective of tertiary education. The average technical enrollment rate is insignificant $(0.34 \%)$ with a maximum of 3 percent.

One can easily grasp the dismal situation in terms of gaps in enrollments between districts. Even with primary enrollment (5-9 age cohort) the range goes from 4 to 75 with MMR of 20. Adult literacy rate varies from 10 to 70 with MMR of 7 . Highest CV and Gini appeared in technical enrollment rates. With low levels and high dispersion, the enrollment beyond age 14 indicates a disturbing situation.

\subsection{Education and Economic Development}

Figure-1 plots average literacy for each development quintile. Two observations emerge. First, female literacy rate is quite low as compared with male literacy at all levels of development. Second, the gap reduces as one moves along the development axis from the lowest (I) to the highest (V) quintile. Another important visual interpretation from this figure is the strong association between economic development and female literacy rate. This phenomenon is much sharper than the male literacy rate.

Figure-2 depicts the movement of the average enrollment rate in various age cohorts and economic development. Although all enrollment rates are positively related with economic development, a sharp reduction of gaps among various enrollment rates is not visible. To some extent, a synchronized movement of development and tertiary enrollment is visible from the figure. 
Figure-1: Average Adult Literacy Rate by Development Quintiles

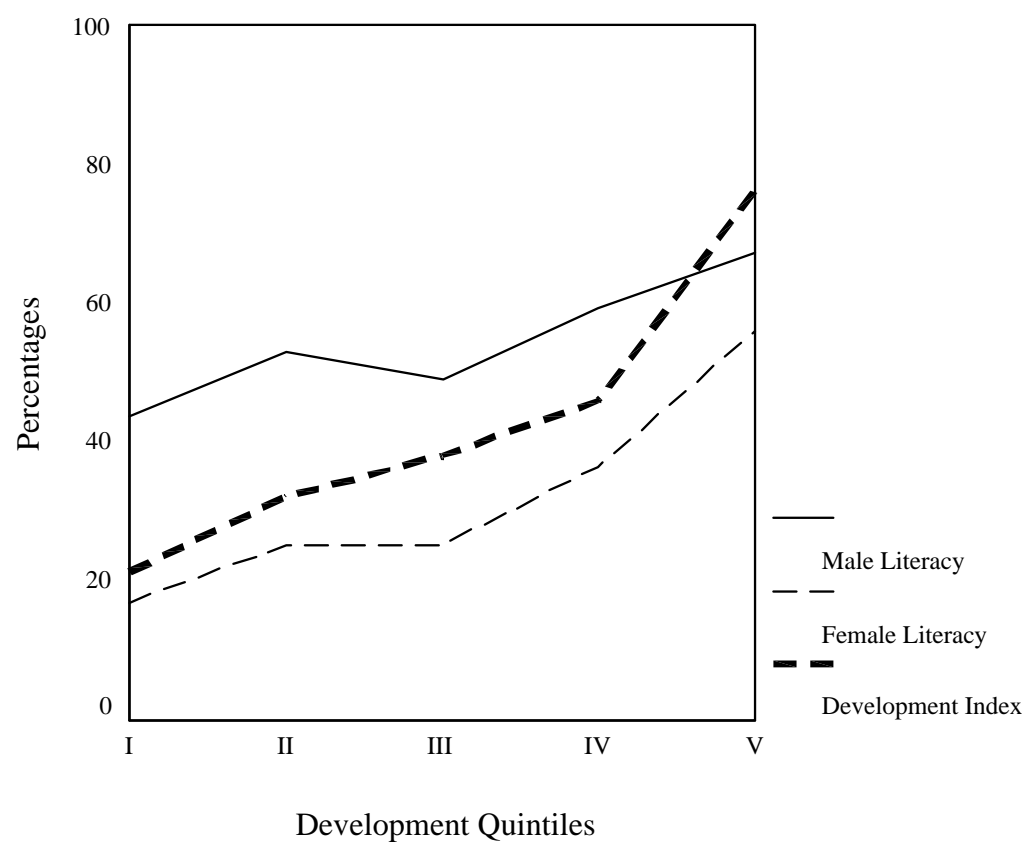

Figure-2: Average Enrollment by Development Quintiles

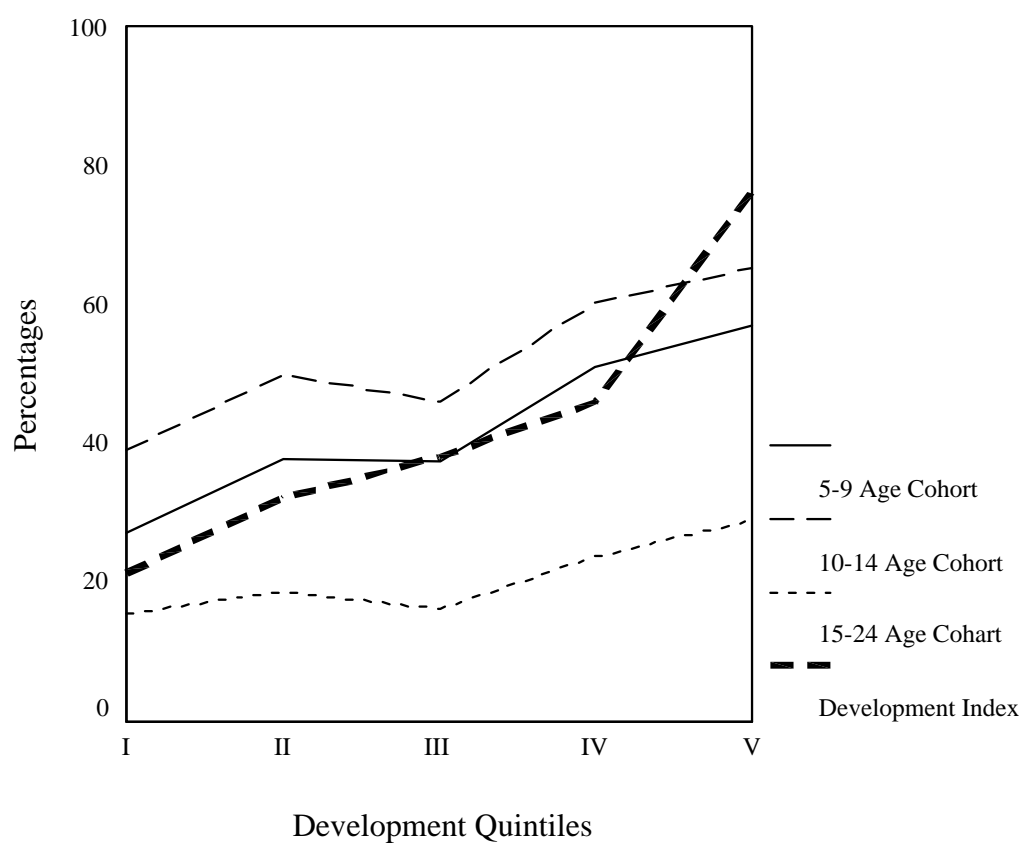


In the absence of district-wise investment or infrastructure data, it would be naive to estimate a multivariate district production function. District labor force may be used as a proxy for the level of physical endowments. Nonetheless and albeit crude, regressing literacy, technical enrollment rates and district labor force participation on the level of economic development reveals interesting information. Table 3 provides these results.

Table-3: Regression Result Dependent Variable Index of Economic Development

\begin{tabular}{lccc}
\hline Explanatory Variables & Coefficient & t-Statistics & Significance \\
\hline Adult Literacy Rate & 0.235 & 2.93 & $0.004^{* * *}$ \\
Technica1/Professional Enrollment & 9.115 & 3.62 & $0.000^{* * *}$ \\
District Labor Force Participation & 0.071 & 6.51 & $0.000^{* * *}$ \\
(Constant) & 15.345 & 6.48 & $0.000^{* * *}$ \\
\hline $\mathrm{R}^{2}$ & & 0.66 & \\
& Adjusted $\mathrm{R}^{2}$ & 0.65 & \\
F-Statistics & $61.39^{* *}$ & \\
\hline
\end{tabular}

** Significant at 1 percent level of significance.

This exercise indicates that coefficients are significant and positively related with the level of economic development. All regression statistics are satisfactory and significant. An important finding of this exercise is the largest marginal effect of technical/professional enrollment. According to the results, a one percent increase in the technical/professional enrollment approximately causes a nine percent increase in the level of economic development.

\subsection{Education Inequality and Economic Development}

Figures 3 to 5 are plotted to visualize the links between education inequality and the level of economic development. For these graphs, coefficient of variation $(\mathrm{CV})$ is computed for each development quintile as a measure of inequality. The figures clearly indicate that education inequality is inversely related with development. Inequality in education is decreasing with an increase in the development level. This phenomenon is much sharper in the case of female literacy. To summarize the enrollment inequality, combined enrollment rates (5-24 years) are plotted with development in Figure-5. The trends are similar to those of the overall literacy rate but not as sharp as the case of female literacy. 


\section{Figure-3: Development Level and Inequality in Adult Literacy Rate}

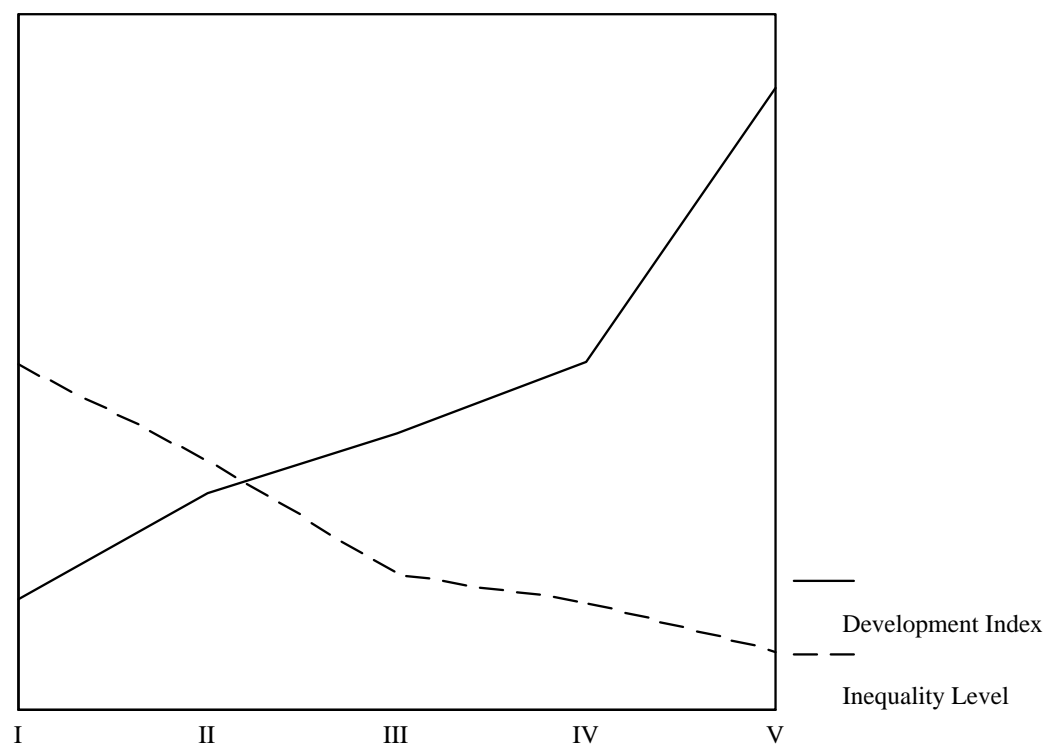

Development Quintiles

Another method of visualizing socioeconomic inequality in education is to draw a Concentration Curve (CC). As discussed in Section 2, in plotting the Concentration Curve, geographical units are ranked according to the socioeconomic status and not according to the educational status. Perfect equality irrespective of socioeconomic status is achieved if the Concentration Curve coincides with the diagonal or line of equality. The further the Concentration Curve lies from the diagonal, the greater the degree of inequality across socioeconomic groups. Figures 6 to 9 demonstrate the extent of socioeconomic inequality with respect to various enrollment rates.

Few observations emerge. For all enrollment rates, socioeconomic inequalities exist and are to the disadvantage of the poor - rates are lower in poor groups.

Inequality in urban areas is high as rural curves are relatively much closer to the line of equality. Rural inequalities if considered alone are relatively higher in primary or secondary levels rather than the tertiary level. It is worth mentioning that these curves represent the dispersion in the distribution of indicators and not the level of indicators. Of course, all education indicators related to rural areas have a much smaller magnitude as compared with their urban counterpart. 
Comparatively the highest socioeconomic inequality is observed in the enrollment of technical/professional education (Figure-9), while the lowest inequality appears in the age cohort of 5-9 (net primary).

Figure-4: Development Level and Inequality in Female Literacy Rate

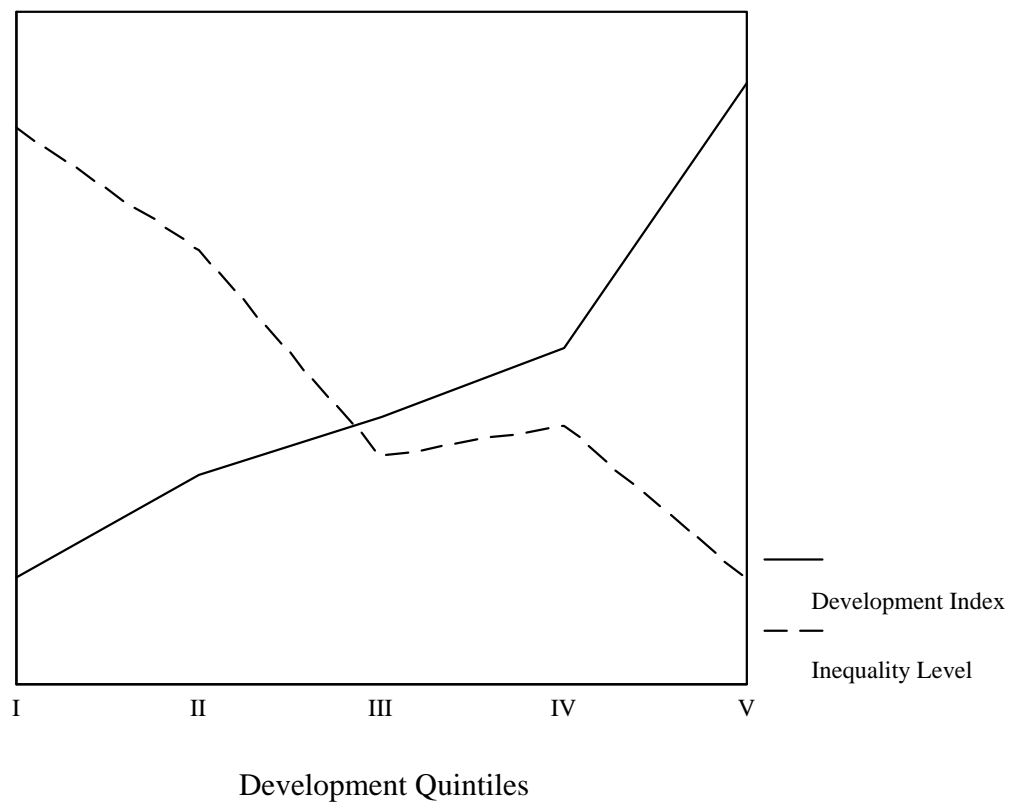

Figure-5: Development Level and Inequality in Combined Enrollment Rate

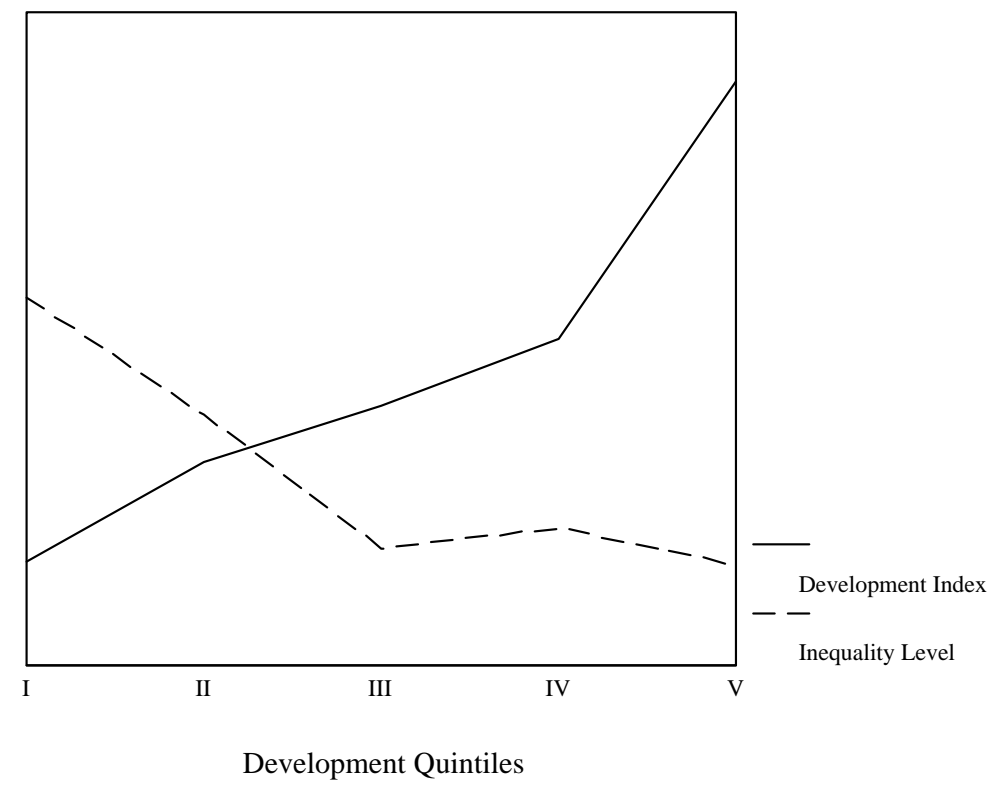


Figure-6: Concentration Curve for Enrollment in 5-9 Age Cohort

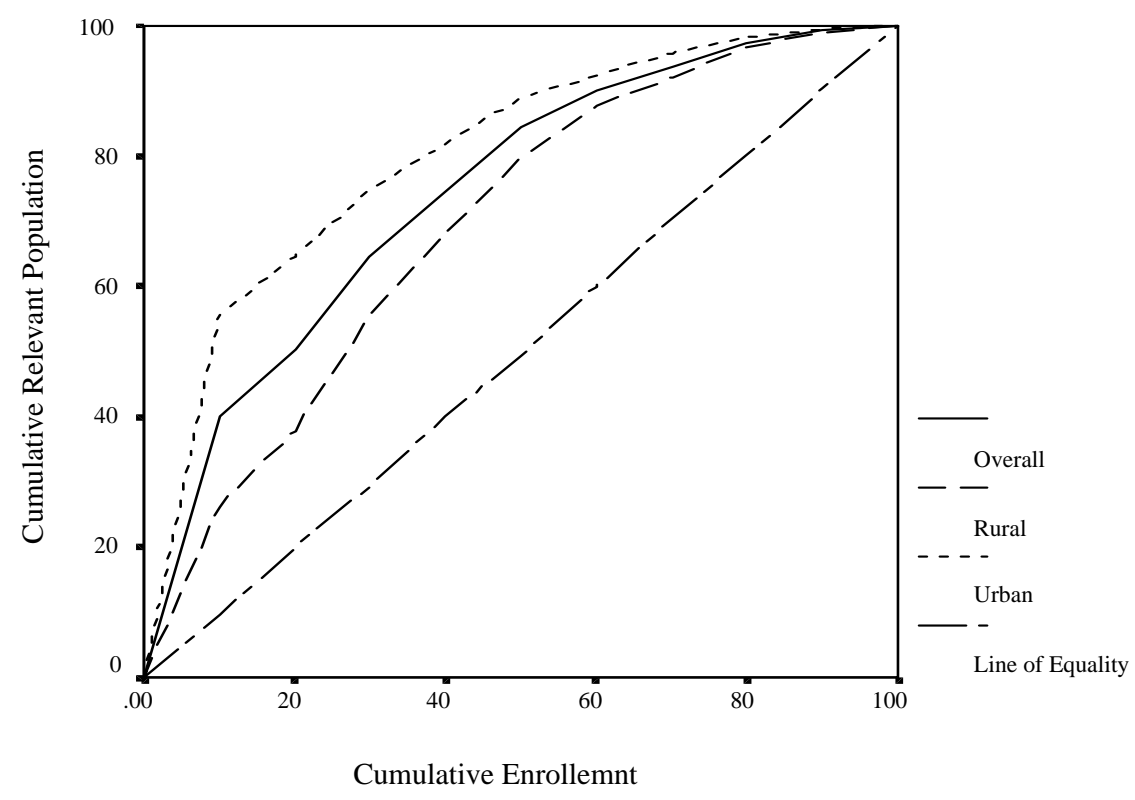

Figure-7: Concentration Curve for Enrollment in 10-14 Age Cohort

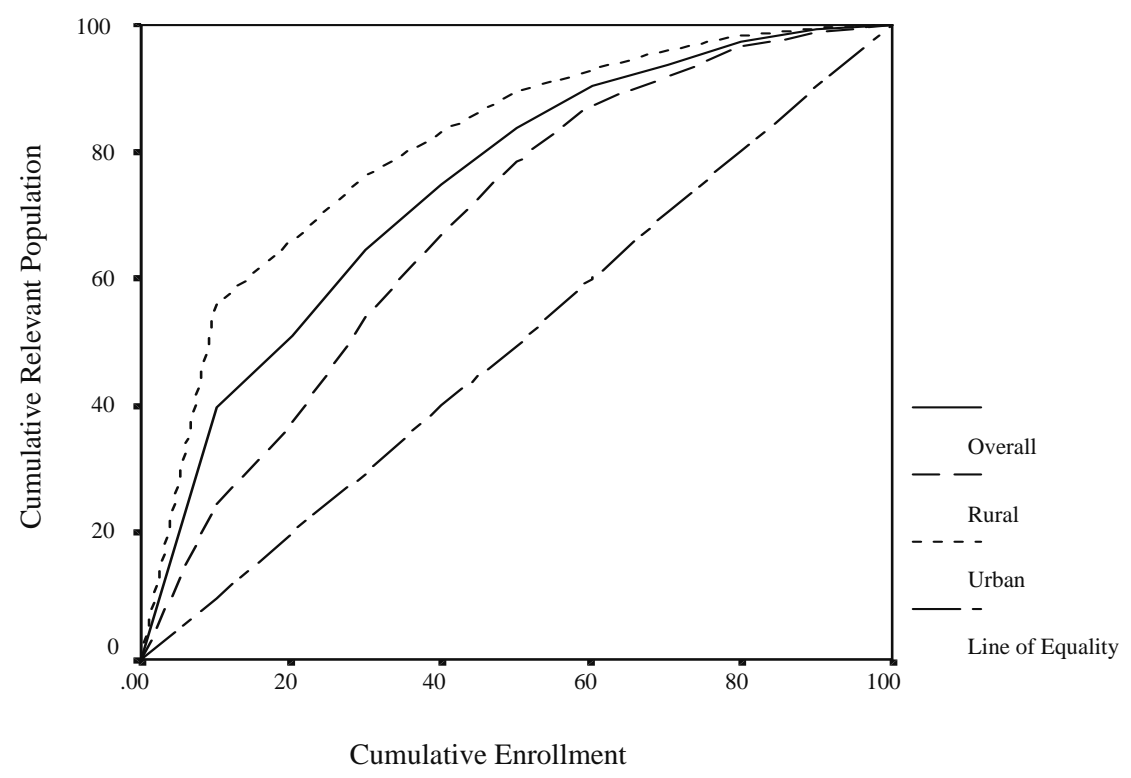


Figure-8: Concentration Curve for General Enrollment in 15-24 Age Cohort

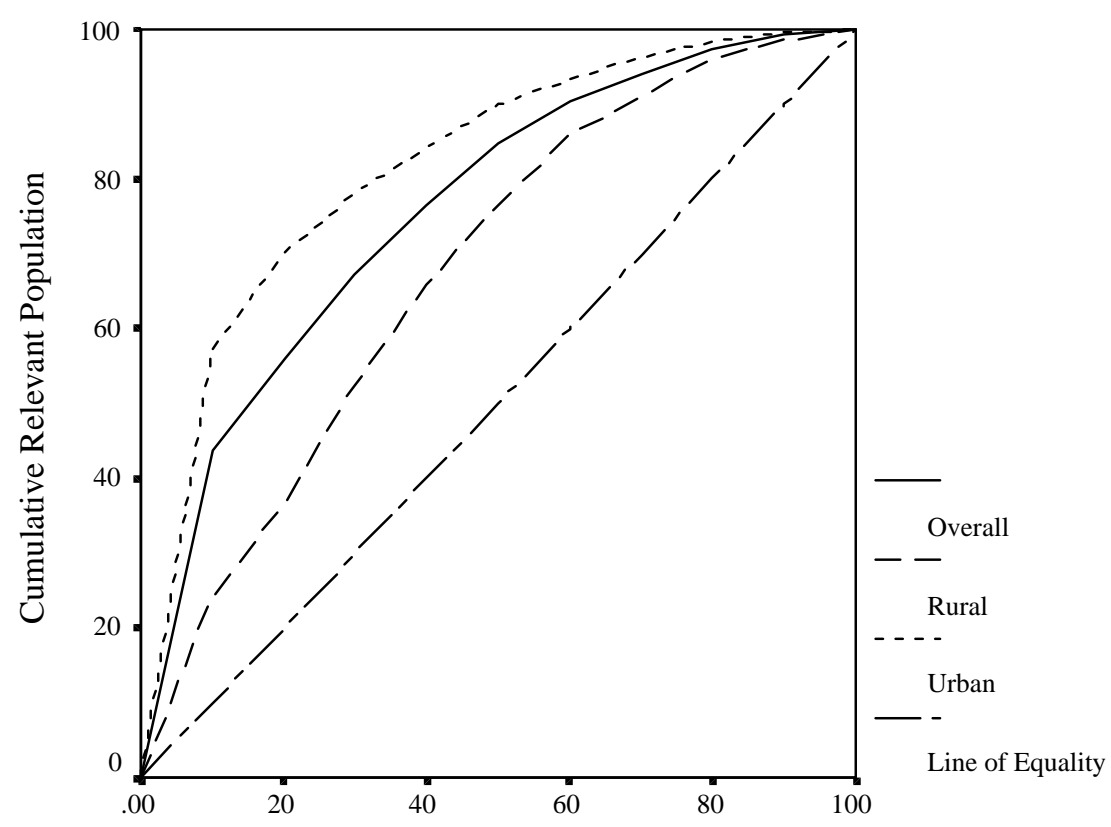

Cumulative Enrollment

Figure 9: Concentration Curve for Technical Enrollment in 15-24 Age Cohort

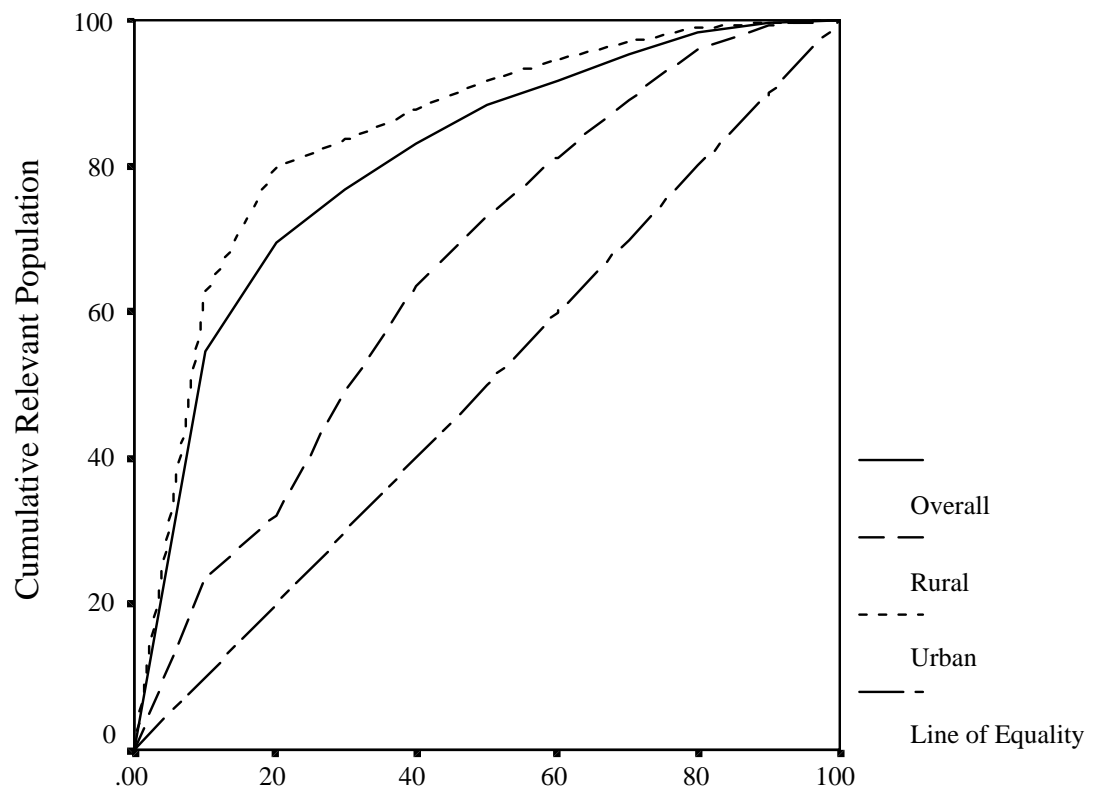

Cumulative Enrollment 


\subsection{The District Education Index}

Pure inequalities in education are analyzed with the help of DEI. In contrast to socioeconomic inequalities, DEI investigates the dispersion in the educational status of districts irrespective of their economic status and measures the average shortfall from a perfect score of 100 percent.

Table-4 presents an overall national picture of education access and inequality. On the average, the value of DEI indicates a shortfall of 64 percent (100-36). In terms of access, females are 14 percentage points behind males thereby indicating that inequality is higher among females than males. The MMR is 29 for female DEI as against 8 for male DEI. Similarly, the coefficient of variation is more than double in the case of female DEI.

Table-4: District Education Index - National Scenario [Average Level and Inequality Measures]

\begin{tabular}{lccccc}
\hline & $\begin{array}{c}\text { Population } \\
\text { Weighted } \\
\text { Average }\end{array}$ & $\begin{array}{c}\text { Minimum } \\
\text { Maximum }\end{array}$ & $\begin{array}{c}\text { Maximum } \\
\text { Minimum } \\
\text { Ratio }\end{array}$ & $\begin{array}{c}\text { Coefficient } \\
\text { of Variation } \\
\text { (\%) }\end{array}$ & $\begin{array}{c}\text { Gini } \\
\text { Index } \\
\text { (\%) }\end{array}$ \\
\hline All Areas & 36 & $6 \rightarrow 61$ & 10 & 49 & 24 \\
Combined & 44 & $8 \rightarrow 67$ & 8 & 35 & 20 \\
Male & 30 & $2 \rightarrow 57$ & 29 & 79 & 34 \\
Female & 32 & $4 \rightarrow 57$ & 14 & 50 & 26 \\
Rural Areas & 41 & $6 \rightarrow 66$ & 11 & 37 & 23 \\
Combined & 23 & $1 \rightarrow 48$ & 48 & 83 & 38 \\
Male & & & & & \\
Female & 51 & $14 \rightarrow 70$ & 5 & 21 & 13 \\
Urban Areas & 56 & $25 \rightarrow 73$ & 3 & 14 & 10 \\
Combined & 44 & $3 \rightarrow 64$ & 21 & 33 & 19 \\
Male & & & & Note: Figures are rounded. \\
Female & & & & &
\end{tabular}


Table-5: District Education Index - Provincial Scenario [Average Level and Inequality Measures for All Areas]

\begin{tabular}{lccccc}
\hline & $\begin{array}{c}\text { Population } \\
\text { Weighted } \\
\text { Average }\end{array}$ & $\begin{array}{c}\text { Minimum } \\
\text { Maximum }\end{array}$ & $\begin{array}{c}\text { Maximum } \\
\text { Minimum } \\
\text { Ratio }\end{array}$ & $\begin{array}{c}\text { Coefficient } \\
\text { of Variation } \\
\text { (\%) }\end{array}$ & $\begin{array}{c}\text { Gini } \\
\text { Index } \\
\text { (\%) }\end{array}$ \\
\hline Male-Female Combined & 40 & $20 \rightarrow 61$ & 3 & 29 & 16 \\
Punjab & 34 & $13 \rightarrow 52$ & 4 & 57 & 19 \\
Sindh & 31 & $7 \rightarrow 48$ & 7 & 34 & 20 \\
NWFP & 23 & $6 \rightarrow 51$ & 9 & 65 & 29 \\
Balochistan & 47 & $26 \rightarrow 67$ & 3 & 22 & 13 \\
Male & 40 & $18 \rightarrow 55$ & 3 & 39 & 16 \\
Punjab & 42 & $12 \rightarrow 58$ & 5 & 25 & 26 \\
Sindh & 29 & $9 \rightarrow 58$ & 6 & 53 & 34 \\
NWFP & & & & & \\
Balochistan & 35 & $14 \rightarrow 57$ & 4 & 41 & 21 \\
Female & 29 & $7 \rightarrow 50$ & 7 & 92 & 25 \\
Punjab & 20 & $2 \rightarrow 39$ & 20 & 60 & 34 \\
Sindh & 15 & $3 \rightarrow 45$ & 15 & 100 & 38 \\
NWFP & & & & Note: Figures are rounded. \\
Balochistan & & & & &
\end{tabular}

A low level of educational status with high inequality ${ }^{4}$ is evident in rural areas. With MMR 48, Gini 38 and with approximately 50 percent lesser average value of DEI, the misery of rural females is also apparent from the table. The position of urban females is also vulnerable, however, to a lesser extent. The highest access and lowest inequality emerged in DEI for urban males.

Table-5 portrays the overall provincial picture, while Tables- 6 and 7 furnish provincial comparison for rural and urban areas respectively. Punjab province is leading with relatively higher values of DEI and lesser inequality.

\footnotetext{
${ }^{4}$ These are pure inequalities in education. Socioeconomic inequalities in education for rural areas are relatively smaller than socioeconomic inequalities for urban areas.
} 
The range between minimum and maximum DEI is also lowest in the Punjab province. Except for female educational status, Sindh lags behind NWFP. However, inequality is relatively higher in NWFP than Sindh. Balochistan, as expected depicts a depressing picture both in terms of average levels and inequality.

There is a pronounced disparity in the provision of education in urban and rural areas. According to Tables-6 and 7, barring Punjab, the average values of urban DEIs are more than double than the rural DEIs. Similarly, magnitude of MMR and other inequality indicators for rural and urban areas are far-off.

Table-6: District Education Index - Provincial Scenario [Average Level and Inequality Measures for Rural Areas]

\begin{tabular}{|c|c|c|c|c|c|}
\hline & $\begin{array}{c}\text { Population } \\
\text { Weighted } \\
\text { Average } \\
\end{array}$ & $\begin{array}{l}\text { Minimum } \\
\rightarrow \\
\text { Maximum }\end{array}$ & $\begin{array}{c}\text { Maximum } \\
\text { Minimum } \\
\text { Ratio } \\
\end{array}$ & $\begin{array}{c}\text { Coefficient } \\
\text { of Variation } \\
(\%) \\
\end{array}$ & $\begin{array}{c}\text { Gini } \\
\text { Index } \\
(\%)\end{array}$ \\
\hline \multicolumn{6}{|c|}{ Male-Female Combined } \\
\hline Punjab & 37 & $16 \rightarrow 57$ & 4 & 31 & 18 \\
\hline Sindh & 27 & $12 \rightarrow 40$ & 3 & 53 & 19 \\
\hline NWFP & 28 & $8 \rightarrow 47$ & 6 & 31 & 20 \\
\hline Balochistan & 19 & $4 \rightarrow 41$ & 10 & 65 & 32 \\
\hline \multicolumn{6}{|l|}{ Male } \\
\hline Punjab & 45 & $23 \rightarrow 66$ & 3 & 24 & 14 \\
\hline Sindh & 35 & $18 \rightarrow 47$ & 3 & 38 & 16 \\
\hline NWFP & 41 & $12 \rightarrow 59$ & 5 & 24 & 16 \\
\hline Balochistan & 25 & $6 \rightarrow 52$ & 9 & 54 & 29 \\
\hline \multicolumn{6}{|l|}{ Female } \\
\hline Punjab & 28 & $8 \rightarrow 48$ & 6 & 45 & 25 \\
\hline Sindh & 18 & $5 \rightarrow 32$ & 6 & 94 & 26 \\
\hline NWFP & 15 & $2 \rightarrow 35$ & 17 & 56 & 35 \\
\hline Balochistan & 11 & $1 \rightarrow 31$ & 31 & 103 & 44 \\
\hline
\end{tabular}


Table-7: District Education Index - Provincial Scenario [Average Level and Inequality Measures for Urban Areas]

\begin{tabular}{lccccc}
\hline & $\begin{array}{c}\text { Population } \\
\text { Weighted } \\
\text { Average }\end{array}$ & $\begin{array}{c}\text { Minimum } \\
\text { Maximum }\end{array}$ & $\begin{array}{c}\text { Maximum } \\
\text { Minimum } \\
\text { Ratio }\end{array}$ & $\begin{array}{c}\text { Coefficient } \\
\text { of Variation } \\
\text { (\%) }\end{array}$ & $\begin{array}{c}\text { Gini } \\
\text { Index } \\
\text { (\%) }\end{array}$ \\
\hline Male-Female Combined & 54 & $42 \rightarrow 70$ & 2 & 12 & 7 \\
Punjab & 48 & $36 \rightarrow 55$ & 2 & 14 & 6 \\
Sindh & 48 & $27 \rightarrow 65$ & 2 & 25 & 14 \\
NWFP & 39 & $14 \rightarrow 58$ & 4 & 32 & 17 \\
Balochistan & 58 & $48 \rightarrow 73$ & 2 & 10 & 6 \\
Male & 54 & $41 \rightarrow 58$ & 1 & 9 & 5 \\
Punjab & 56 & $35 \rightarrow 69$ & 2 & 17 & 10 \\
Sindh & 48 & $25 \rightarrow 64$ & 3 & 25 & 14 \\
NWFP & & & & & \\
Balochistan & 49 & $34 \rightarrow 63$ & 2 & 15 & 9 \\
Female & 40 & $29 \rightarrow 50$ & 2 & 24 & 8 \\
Punjab & 39 & $19 \rightarrow 58$ & 3 & 38 & 21 \\
Sindh & 28 & $3 \rightarrow 49$ & 16 & 47 & 24 \\
NWFP & & & Note: Figures are rounded. \\
Balochistan & & & & &
\end{tabular}

In a rural context, Balochistan, as expected, lags behind and all magnitudes are far-off from other provinces. Rural NWFP's performance in terms of access is much better than Sindh as average levels of DEIs are higher. Population adjusted coefficients of variation are also lower than in Sindh. The situation in rural Sindh is, therefore depressing. Rural Punjab is ahead in terms of higher access and lower inequality. More or less similar patterns or trends are observed in urban areas with different magnitudes (higher value of DEI and lower level of inequality).

For public intervention and policy purposes ${ }^{5}$, an indicative exercise is carried out. Districts, which are at the bottom of DEI (lowest three

${ }^{5}$ Full ranking of districts of Pakistan according to DEI is available and may be provided on request. 
deciles), are grouped in Table 8 . Out of 26 districts of Balochistan, 14 are in $9^{\text {th }}$ and $10^{\text {th }}$ deciles. In NWFP only 2 districts out of 24 are in the $10^{\text {th }}$ decile. In Punjab, the position is relatively better and only 1 district out of 34 appeared in the table, which is in the $8^{\text {th }}$ decile. In Sindh province, 5 districts out of 16 are at the bottom of DEI (lowest 30 percent).

Table-8: Distribution of Districts Across Three Lowest Deciles of DEI

\begin{tabular}{|c|c|c|c|}
\hline \multirow[b]{2}{*}{ Province } & \multicolumn{3}{|c|}{ Districts Position } \\
\hline & $\begin{array}{c}\text { Third Lowest } \\
8^{\text {th }} \text { Decile }\end{array}$ & $\begin{array}{c}\text { Seocond Lowest } \\
9^{\text {th }} \text { Decile }\end{array}$ & $\begin{array}{c}\text { Lowest } \\
10^{\text {th }} \text { Decile }\end{array}$ \\
\hline \multirow[t]{8}{*}{ Balochistan } & Killa Saifullah & Zhob & Jha1 Magsi \\
\hline & Lasbela & Killa Abdullah & Kohlu \\
\hline & Sibi & Kalat & Dera Bugti \\
\hline & & Bolan & Nasirabad \\
\hline & & Khuzdar & Musa Khe1 \\
\hline & & Barkhan & Awaran \\
\hline & & Jafarabad & Kharan \\
\hline & & Loralai & \\
\hline \multirow[t]{3}{*}{ NWFP } & Upper Dir & Batagram & Kohistan \\
\hline & Buneer & & Shangla \\
\hline & Tank & & \\
\hline \multirow[t]{3}{*}{ Sindh } & Badin & Thatta & Tharparkar \\
\hline & Jacobabad & & \\
\hline & Shikarpur & & \\
\hline Punjab & Rajanpur & & \\
\hline
\end{tabular}

Note: Districts are sorted in ascending order (lowest to highest) according to the value of DEI in each category and province. There are 26, 24, 16 and 34 districts in Balochistan, NWFP, Sindh and Punjab provinces respectively.

\section{Concluding Remarks}

Policy makers, researchers and academics have increasingly recognized the links between inequality in education and other social and economic phenomena. As economic activity becomes increasingly knowledge based, disparities in educational opportunity play a more important role in 
determining the distribution of income and poverty. A greater equity in the distribution of educational opportunities enables the poor to capture a larger share of the benefits of economic growth, and in turn contributes to higher growth rates. In contrast, large-scale exclusion from educational opportunities results in lower economic growth and persistent income inequality.

Countries ratifying the United Nations (UN) convention on the Rights of the Child recognize the right to education "on the basis of equal opportunity". Therefore to promote this right to education, access should be provided without any discrimination.

This research appraises education inequalities in Pakistan at the district level. Pure inequalities in education are examined through the District Education Index (DEI). DEI is a composite index and includes enrollments at various levels and adult literacy rates. In developing DEI, only Population Census data are used to avoid any reservations regarding the quality of education data. Socioeconomic inequalities are also studied by linking DEI with the level of economic development of districts. For this purpose, a composite Index of Economic Development (IED) is constructed with various welfare indicators related to income and wealth, modernization of agriculture, transport and communication, housing quality and housing services.

Results indicate low levels of educational status with high inequality. The most vulnerable groups are rural areas, Balochistan province, and rural females. More than half of the districts have a value of DEI less than average, which is reflective of the gravity of the situation. This condition of knowledge divide demands national education action, which must be effective and not merely an exercise in tokenism. Socioeconomic inequalities in education also require integration of education into national poverty reduction strategies. 


\section{References}

Filmer, Deon and Pritchett, Lant, 1999, "The effect of household wealth on educational attainment: evidence from 35 countries" Population and Development Review, 25(1): 85-120.

Kakwani, Nanak, 1980 Inequality and Poverty - Methods of Estimation and Policy Applications, The World Bank, Oxford University Press

Pakistan Census Organization, 1988, District Census Reports

Pasha H. A. and Hassan, T., 1982, "Development Ranking of the Districts of Pakistan”, Pakistan Journal of Applied Economics, (12).

Watkins, Kevin, 2001, “The Oxfam Education Report”, Oxfam International. 